\title{
PERFORMANCE EVALUATION OF (ALCRN) PVD COATED CBN INSERTS ON MACHINING OF INCONEL 718
}

\author{
P Jeyapandiarajan ${ }^{1}$, M. Anthony Xavior $^{1 *}$, Arivazhagan Anbalagan² \\ ${ }^{1}$ Vellore Institute of Technology, School of Mechanical Engineering, Vellore, India \\ ${ }^{2}$ Robert Gordon University, Aberdeen, AB10 7QB, Scotland, UK \\ ${ }^{*}$ Corresponding author; e-mail: manthonyxavior@vit.ac.in
}

\begin{abstract}
This research work focuses on the experimental investigations conducted using uncoated cBN tool and (AICrN) PVD Coated cBN tool for turning Inconel 718. Two different sets of experiments - one with uncoated $\mathrm{cBN}$ and another with coated $\mathrm{cBN}$ inserts were conducted considering three different levels of cutting speeds, feed rates and depth of cuts. The performance of the coated cBN over the uncoated inserts were evaluated and it was found that the AICrN coated cBN inserts can produce 10-12\% drop in the cutting force, $15 \%$ reduction in the flank wear and $10 \%$ reduction in the surface roughness.
\end{abstract}

\section{Keywords:}

Inconel 718; Machining; cBN; AICrN PVD Coating; Wear; Surface Roughness

\section{INTRODUCTION}

Inconel 718 , as it is known, is considered as one of the difficult - to - machine materials due to its mechanical, physical and thermal properties. Attempts have been made by many researchers in the past to improve the machinability aspects of Inconel 718 by introducing new cutting tool materials, varying the cutting parameters and cutting condition / environment etc. In this direction an attempt has been made to enhance the capability of existing $\mathrm{CBN}$ insert by providing a PVD coating on it and investigate its machinability. Machinability study on the material cannot be complete without studying about the tool insert. Cubic boron nitride has cubic atomic structure with very good hardness. $\mathrm{CBN}$ inserts have the ability to withstand high temperature and remain wear resistant. These two properties lead to improved machinability by increasing the tool life. Further, extending the tool life of the existing tool would add advantage over procuring a new tool. An ideal coating should have proper bonding, higher strength at high temperature, chemical stability, lubrication property, thermal barrier, etc. [Zhang 2014] [Klocke 1999]. Tool wear directly or indirectly affects the cutting temperature, cutting force, surface integrity, tool life and also the production cost [Thakur 2016]. Coating provide better heat resistance by covering the tool from the heat generated at the primary and secondary zones [Ko"nig 1992] [J. Rech 2004]. Overall machining time can be improved by $60 \%$ while comparing on the surface finish obtained in grinding process with the hard turning operation [H.K. Tönshoff 2000]. Coating on tool would improve the tool life. It has been reported that the hard coating definitely improves the tool life, surface integrity on the machined workpiece but the utility of coating are still restricted over hard materials [L.A. D brzański 2005] [M. Sokovic 2006] [A.A. Vereschaka 2017] [C.S. Kumar 2017]. PVD and CVD coating techniques had shown better performance than other coating methods. The performance of the PVD coated tools are proved to be better than CVD coated tools in terms of cutting force and surface roughness [Ezugwu 2005]. TiAIN/TiCN PVD and $\mathrm{TiCN} / \mathrm{Al}_{2} \mathrm{O}_{3}$ CVD coated tools were studied and reported that the PVD coated tool had performed outstandingly under ideal machining conditions [A. Thakur 2016]. Addition of ductile phase to the mixed ceramic composite that are brittle in nature could increase the fracture toughness of the cutting tool [C.S. Kumar 2017]. TiN thin film coat with alumina base mixed ceramic coating has improved the tool life and surface properties of the material [K. Aslantas 2012]. It was also reported that AITiN, AITiCrN, TiN/TiAIN PVD coated carbide inserts used for machining SS304 showed high abrasive and chipping wear with AITiN coated tool. TiN/TiAIN PVD coated tool showed higher cutting forces than AITiN and AITiCrN. AITiCrN resulted in better performance due to its high oxidation resistance and good adhesion properties [A.P. Kulkarni 2015]. AICrN coated carbide inserts indicated $95 \%$ better performance than TiAIN coated carbide insert during dry and wet machining. It was also reported that $33 \%$ higher depth of cut can be used while machining with AICrN coat due to its higher thermal resistance even during harsh cutting conditions [Y.J. Lin 2008]. Ti- free coatings had improved the machinability to a greater extend in all means. AICrN with its excellent oxidation property and wear resistant nature suits better for milling and drilling on a steel material [W. Kalss 2006]. Presence of aluminium in $\mathrm{CrN}$ shifts the peak oxidation to a temperature ranging from 
$950^{\circ} \mathrm{C}$ to $1050^{\circ} \mathrm{C}$ because of its oxidation property forming $\mathrm{Al}_{2} \mathrm{O}_{3}$ heat resistant layer protecting the tool material and the binders. In the absence of $\mathrm{Al}, \mathrm{CrN}$ layer gets oxidizes by $800^{\circ} \mathrm{C}$ completely [A.E. Reiter 2005]. While comparing the coatings of AITiN, AICrN, AICrSiWN on the carbide tool, it was concluded that AICrN outperformed the other coatings in terms of thermal stability and oxidation characteristics. AICrSiWN resulted in highest hardness followed by AICrN and AICrSiWN but the hardness value drops drastically as the temperature increases by $700^{\circ} \mathrm{C}$. Such results added points for the usage of $\mathrm{AICrN}$ coated tool [Y.P.Feng 2014]. From the literature, AICrN showed better performance than other coating. PCBN tool performs excellently while machining of hard materials with HRC greater than 36 [Gutnichenko, O. 2017]. PCBN tool results in lower surface roughness even at the end of the tool life but use of fresh carbide tools shows 10 times worst roughness value [Díaz-Álvarez, 2018]. Titanium Nitride coated cBN tool demonstarted longer tool life approximately $20 \%$ greater than the coated tool [Zhou, 2012]. SiC whisker-reinforced alumina, coated PCBN tool life results indicate that advantage of the coating over limited cutting speed [Bushlya, 2013]. CVD coating methods results in higher coating thickness than PVD coating process. In this research work, it is planned to provide a thin layer coating over $\mathrm{cBN}$ and therefore, its decided to proceed with PVD Coating. Eventhough, CBN tool has highest hardness value next to diamond, all these factors has sparked the idea of coating $\mathrm{cBN}$ with AICrN through PVD process. Contributions to the research society with this combination remains still lacking at this stage.

\section{EXPERIMENTAL DESIGN}

Turning operation was performed on the Inconel 718 specimen of diameter $32 \mathrm{~mm}$ and length $500 \mathrm{~mm}$ using computer numerical control (CNC) machine - Simple Turn 5075 model from ACE Micromatic Group. This machine has the capability to vary the spindle speed from 50 to 4000 rpm. The image of the ACE Simple Turn machine is presented in fig.1.
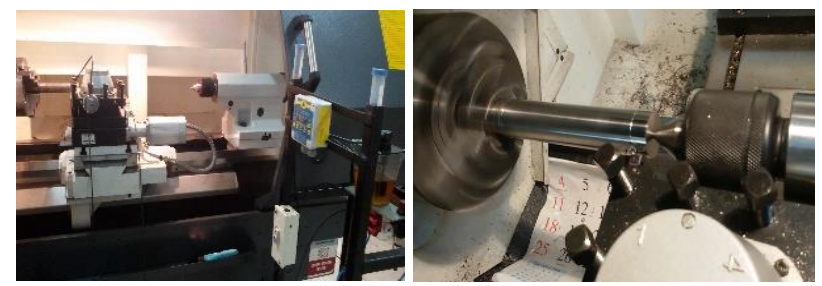

Fig. 1 ACE Micromatic Simple Turn machine used for machining Inconel 718.

Kistler dynamometer is used to measure the cutting force in all three directions Fx, Fy and Fz representing the feed force, radial force and the tangential force respectively. Model 9257B is used to sense the small dynamic changes which is amplified to a larger scale that can be recorded comfortably. Surface roughness values are measured using marsurf GD 120 surface profilometer as shown in fig. 2. Surface roughness was measured on the specimen for a length of $4 \mathrm{~mm}$ providing a cut off of 0.8 micron. Four readings were measured on each surface and their average values were taken for the analysis. Tool wear was measured using TESA VISIO V300DCC 3D measuring machine as shown in fig. 3. Tool holder (PCLNR2525M12) and Cubic Boron Nitride (cBN) grade KB1630 (CNGA120408S01025MT) cutting insert were procured from M/s Kennametal. Diamond shaped insert with nose radius of $0.8 \mathrm{~mm}$ were used for experimentation. The inserts were coated with AICrN material through PVD process. Machining experiments were carried out using coated inserts under dry condition. Four trails were taken for each parameteric settings, considering the machining length as $30 \mathrm{~mm}$ for all machining trials as shown in table1.

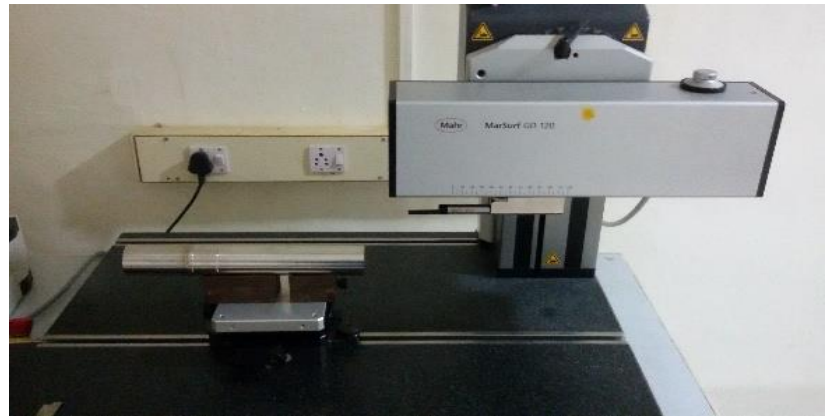

Fig. 2. Marsurf GD 120 surface roughness measuring instrument.

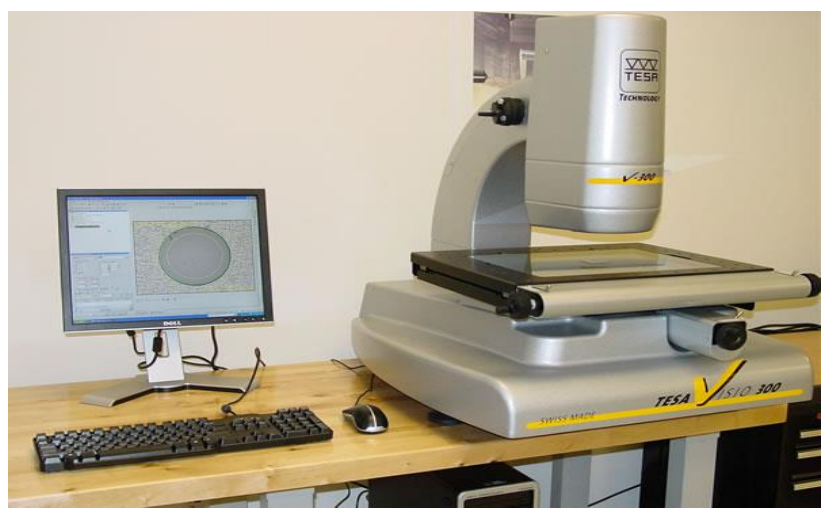

Fig. 3. TESA VISIO V300DCC machine used for the tool wear study.

\section{COATING METHODOLOGY}

Research was conducted on the AICrN coated cBN tool, and therefore, it is necessary to understand the coating methodology used. A heat treated monolayer coating of AICrN was deposited on a cBN substrate by cathodic circular segment (arc PVD) utilizing a Bias and Cathodic Arc Evaporation. The coating material Al70Cr30 alloy was utilized in a controlled nitrogen atmosphere during the PVD process and the coating duration was adjusted to get a layer thickness of $4 \mu \mathrm{m}$. In order to ensure the nitriding of the compound, the coating was deposited under a nitrogen atmosphere and the sample was heat-treated under inert atmosphere for four hours at a temperature of $500^{\circ} \mathrm{C}$. Thermal therapy was performed to modify the microstructure of the cover, to extend nitrogen dissemination, and to cause AIN precipitates to grow and develop. PVD coating required high vacuum chamber with a pressure range of $10^{-2}$ to $10^{-6}$ Torr. The process usually take place between 50 and $500^{\circ} \mathrm{C}$. Substrate to be coated is to be preheated and plasma cleaned. Heat treatment additionally done is extremely useful for eliminating the amorphous phases that form during the coating operation and for making the phases crystalline and for improving adhesion between the coating and substratum. Furthermore, heat treatment helps improve structural integrity and reduce stress and fragility in coatings. The PVD coating facility which was used for coating AICrN in this research work is shown in Fig. 4. 


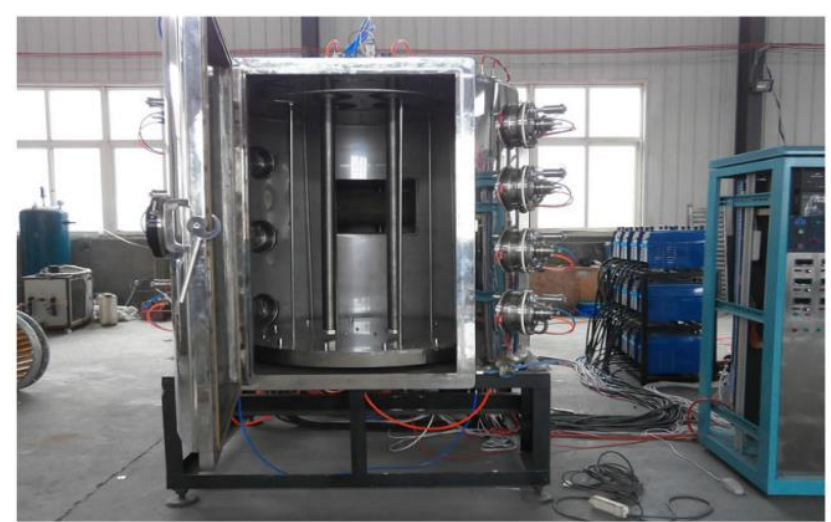

Fig. 4. PVD Coating Facility

\section{RESULTS AND DISCUSSION}

\subsection{Cutting Force Analysis}

Machining trials were performed as per L9 Taguchi's Orthogonal Array with three parameters, each with three levels as shown in table.1. Cutting force study would provide an insight about the parameteric values that contribute to the cause. Sustainable manufacturing is the current trend and the sustainablity of the process depends on various aspects including environmental impact. Lower the production rate causes higher power consumption and delayed work, ultimately increasing the production cost. Optimal parameter would require minimum operational cost of the product.

Table: 1 Cutting parameters for machining

\begin{tabular}{|c|c|c|c|c|}
\hline $\begin{array}{c}\text { Cutting } \\
\text { speed } \\
\begin{array}{c}\text { Vc } \\
(\mathrm{m} / \mathrm{min})\end{array}\end{array}$ & $\begin{array}{c}\text { Depth } \\
\text { of cut } \\
\text { ap } \\
(\mathrm{mm})\end{array}$ & $\begin{array}{c}\text { Feed } \\
\text { rate } \\
\mathrm{f} \\
(\mathrm{mm} / \mathrm{rev})\end{array}$ & $\begin{array}{c}\text { Cutting } \\
\text { forces } \\
\text { Fc (N) } \\
\text { Uncoated } \\
\text { tool (UC) }\end{array}$ & $\begin{array}{l}\text { Cutting } \\
\text { Forces } \\
\text { Fc (N) } \\
\text { Coated } \\
\text { tool (c) }\end{array}$ \\
\hline 60 & 0.2 & 0.08 & 109.21 & 96.83 \\
\hline 60 & 0.4 & 0.12 & 213.65 & 156.37 \\
\hline 60 & 0.6 & 0.16 & 340.13 & 310.61 \\
\hline 90 & 0.2 & 0.12 & 127.29 & 113.49 \\
\hline 90 & 0.4 & 0.16 & 246.42 & 202.64 \\
\hline 90 & 0.6 & 0.08 & 272.49 & 245.77 \\
\hline 120 & 0.2 & 0.16 & 148.73 & 213.92 \\
\hline 120 & 0.4 & 0.08 & 184.72 & 159.83 \\
\hline 120 & 0.6 & 0.12 & 311.46 & 270.75 \\
\hline
\end{tabular}

Cutting force being the primary parameter in cost reduction and machining time, it's necessary to understand its impact on the machining parameters. Cutting forces are monitored and recorded through the online system coupled with the Kistler dynamometer.

Energy consumption reduces as the cutting speed and feed increases as reported by Nur et. al., 2021. Similarly Fig.5 shows the cutting force analysis at fixed depth of cut as a) $0.2 \mathrm{~mm}$, b) $0.4 \mathrm{~mm}$ and c) $0.6 \mathrm{~mm}$. Fig. 5 indicates that the cutting force increases gradually as the speed is increasing in fig. 5(a), but in fig. 5(b) and 5(c) it seems to have a mixed trend.
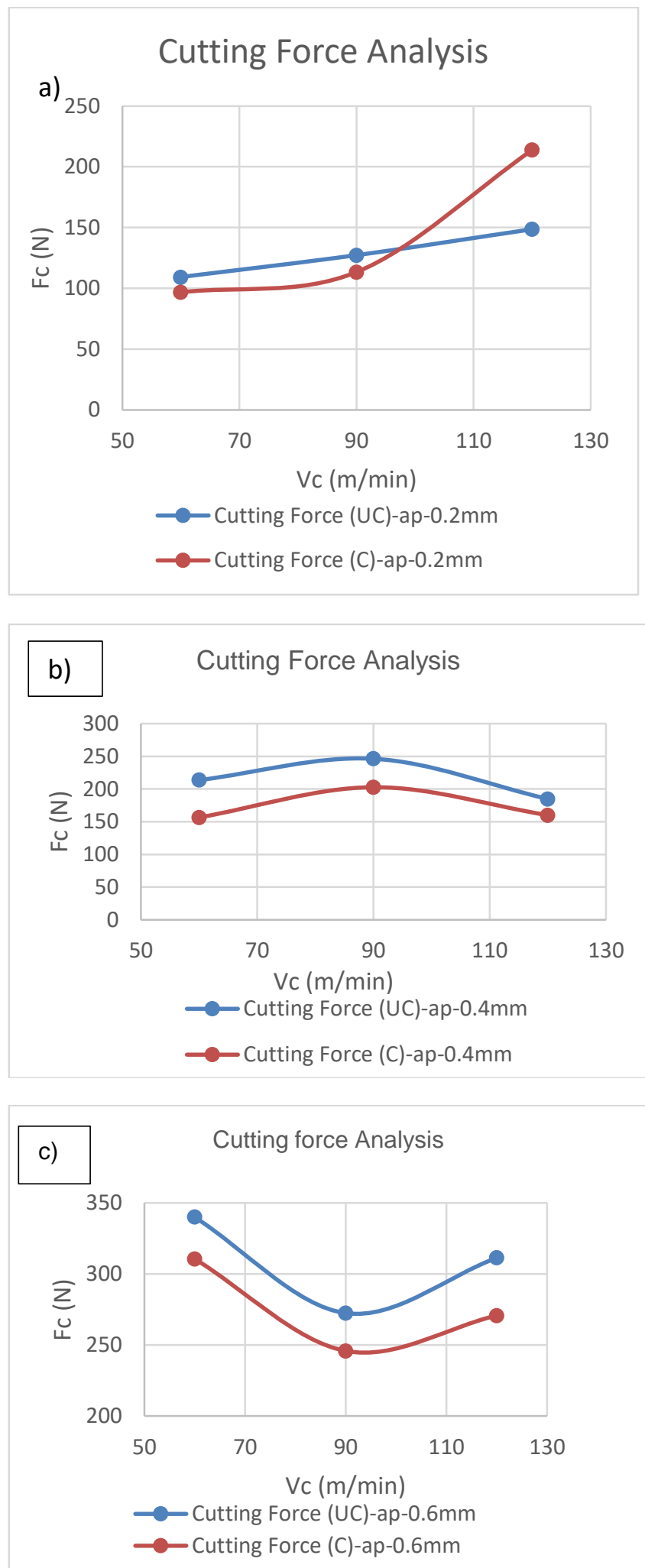

Fig. 5 Cutting force analysis with coated (c) and uncoated (UC) $c B N$ tool at varying depth of cuts : a) at depth of cut (ap) $-0.2 \mathrm{~mm} \mathrm{~b}$ ) ap - $0.4 \mathrm{~mm}$ and c) ap $-0.6 \mathrm{~mm}$.

Variations in the observed cutting forces can be attributed to the change in the feed rate from 0.0 .8 to $0.16 \mathrm{~mm} / \mathrm{rev}$ and the cutting speeds together which, decides on the contact duration of tool and the work piece. Cutting force decreases as the cutting speed increases from $60 \mathrm{~m} / \mathrm{min}$ to $120 \mathrm{~m} / \mathrm{min}$ for fixed depth of cut and feed rate. When the feed rate is increased from $0.08 \mathrm{~mm} / \mathrm{rev}$ to $0.16 \mathrm{~mm} / \mathrm{rev}$ the 
cutting force increases gradually as shown in fig. 5(a). Similar findings were reported by Nur $\mathrm{R}$ et. al. [2021]. In fig. 5 blue curve indicates the results of the uncoated cBN tool results and orange curve indicates the results of coated cBN tool. AICrN coating has reduced the cutting force in all levels. Cutting force has been reduced by $10-12 \%$ while machining with a coated insert when compared with the uncoated $\mathrm{cBN}$ tool. AICrN coating on the $\mathrm{cBN}$ tool costs only $3 \%$ of the price of $\mathrm{cBN}$ tool which can reduce the cutting force by $10-12 \%$. AlCrN coating provide $\mathrm{Al}_{2} \mathrm{O}_{3}$ formation on top surface of the coat which acts as the thermal barrier to heat generated at the work piece - tool interaction zone. AICrN layer prevent the binders being exposed to such thermal conditions sustaining its hot hardness strength for a longer period. It was also reported that $\mathrm{AICrN}$ has higher thermal stability even at elevated temperature as shown in fig. 6 [Y.P.Feng 2014]. Figure 6 indicates that the hardness value remains at $34 \mathrm{GPa}$ $\left(\mathrm{HV}_{8 \mathrm{mN}}\right)$ for AICrSiWN whereas $\mathrm{AICrN}$ has $32 \mathrm{GPa}$ at ambient temperature. As the temperature increases beyond $700^{\circ} \mathrm{C}$ the value drops below $20 \mathrm{GPa}$ for AICrSiWN but $\mathrm{AICrN}$ shows gradual reduction and sustains at $24 \mathrm{GPa}$ $\left(\mathrm{HV}_{8 \mathrm{mN}}\right)$ beyond $1100^{\circ} \mathrm{C}$. While machining, the recorded temperature was about to be $900^{\circ} \mathrm{C}$ [Ogedengbe 2012] which is far behind the required temperature.

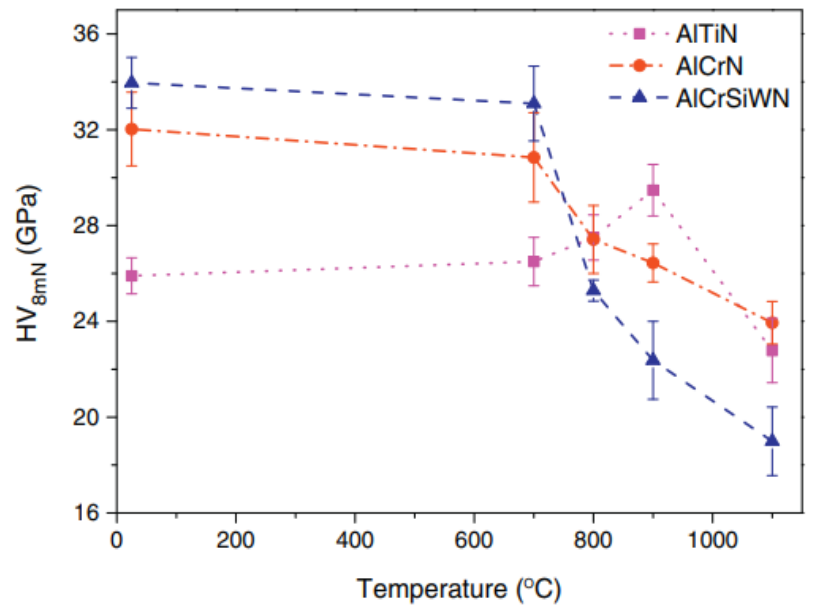

Fig.6 Thermal stability and oxidation behavior of AITiN, AlCrN and AlCrSiWN coatings

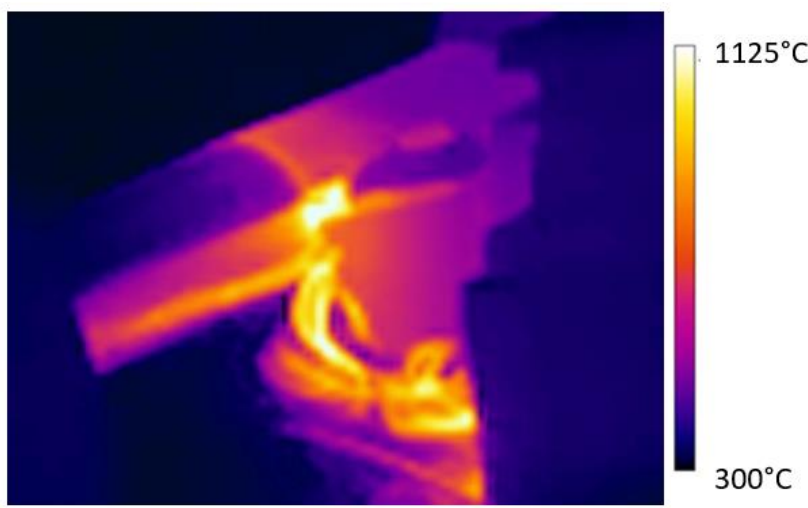

Fig.7 Thermal image captured during machining of coated tool.

Thermal image captured during machining indicates the highest temperature recorded was $1125^{\circ} \mathrm{C}$ as shown in fig.7. Highest temperture can be visualized in the tool-work interphase region and followed with chip flow direction. From fig. 7 it can be understood that tool region shows lower temperature than interaction zone. Its caused due to the AICrN coating which acted as the thermal barrier.

\subsection{Wear Analysis}

Wear on $\mathrm{cBN}$ tool are caused during machining at the higher speeds. The predominant wear on the tool occurs in flank and rake side named as flank wear and crater wear respectively. Flank face being the primary contact surface of the tool with workpiece, the wear occurred on it is taken into account for analysis. Fig. 8 and Fig. 10 shows the SEM image of AlCrN coated cBN insert after machining at cutting speed $120 \mathrm{~m} / \mathrm{min}$, feed $0.08 \mathrm{~mm} / \mathrm{rev}$ and depth of cut 0.4 $\mathrm{mm}$. Fig. 9 and Fig. 11 shows EDX analysis of the surface elements present on the insert.

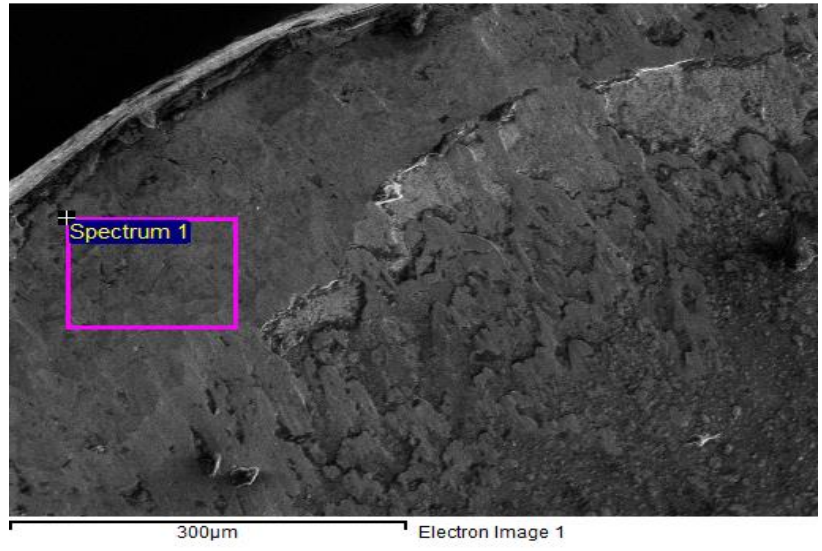

Fig. 8 SEM images of AICrN coated Insert (Spectrum 1)

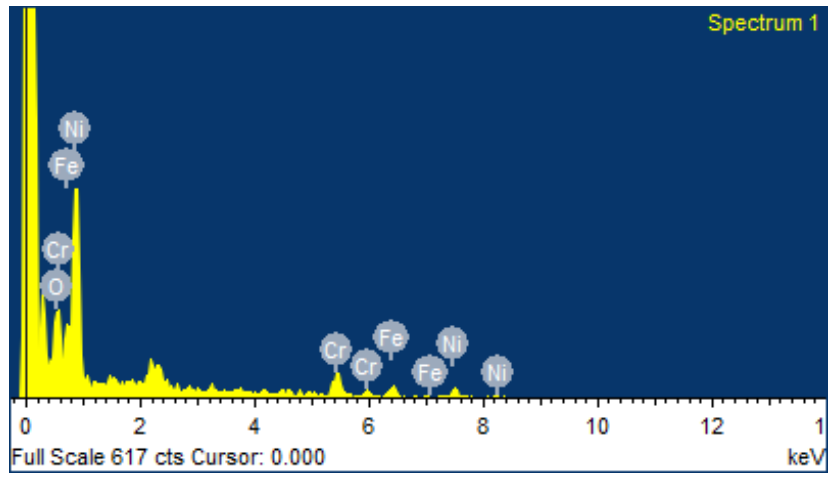

Fig.9 SEM-EDX Analysis of AICrN coated Insert (Spectrum1)

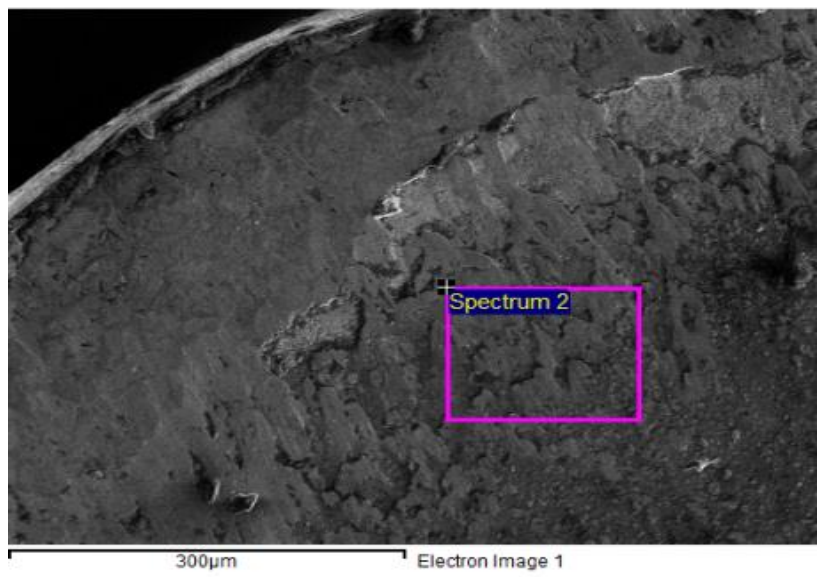

Fig. 10 SEM images of AICrN coated Insert (Spectrum 2) 


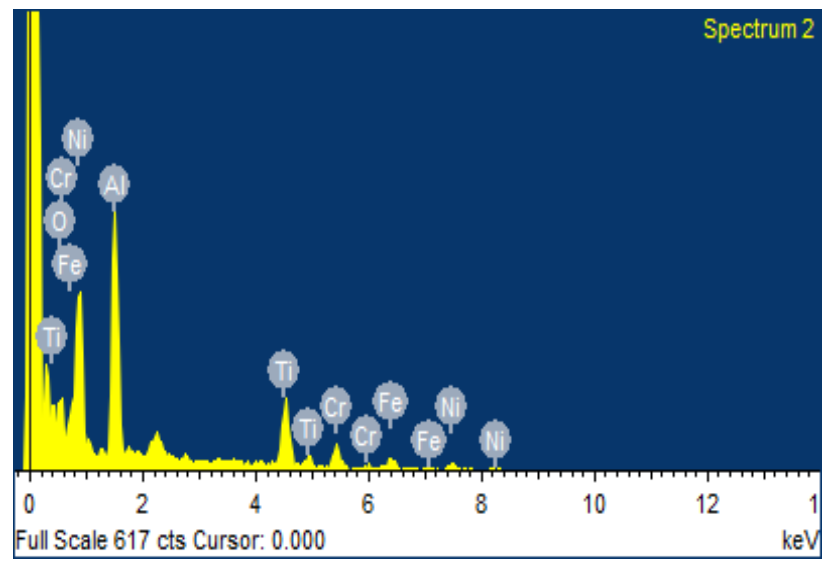

Fig.11 SEM-EDX analysis of AICrN coated Insert (Spectrum 2)

Fig. 8 and Fig.10 shows the rake side of the coated insert subjected to crater wear caused due to the chip flow. Spectrum spot selected on the worn zone of rake face in fig. 8 can be seen and the corresponding analysis indicated in fig. 9 shows the elements of the insert with no clue of $\mathrm{Al}$ presence. On the same insert, spectrum spot moved away from the wear zone of the rake face as shown in fig.10. The corresponding Energy Dispersive X-Ray analysis (EDX) shown in fig. 11 indicated the presence of $\mathrm{Al}, \mathrm{Cr}$ which indicates the AICrN coated surface being worn out. Edges of the insert remain in the proper shape and form, signs of damages not visible due to protective coating of AICrN.

Taguchi analysis carried out using minitab18 to optimize the variable by controlling the "signal to noise ratio" are shown in table 2. Response table indicates the variable that causes higher noise signal known as the uncontrollable variant over parameters as controllable variant using the statistical formula as given in equation.1. Accordingly, in table 2, the delta value remain high for the feed rate when machined with uncoated cBN insert at 4.19 while comparing with the delta value of the other parameters taken into consideration. Feed rate has been ranked as 1 , causing highest noise in the system. Similar type of results are seen with coated cBN insert as shown in table 3. In table 3, feed rate remains with rank 1 having the delta value 3.02 but cutting speed, depth of cut has ranked $2 \& 3$ with delta value as 0.87 and 0.47 respectively. It can be inferred that feed rate has more influence thereby, controlling the feed rate can change the flank wear significantly. This can be more evidentially seen in $\mathrm{S} / \mathrm{N}$ ratio curves, as depicted in fig.12 for uncoated $\mathrm{cBN}$ insert and fig. 13 for coated $\mathrm{cBN}$ insert. Fig. 12 explains the data given in table 2 , feed rate has the maximum spread in the $\mathrm{S} / \mathrm{N}$ ratio curve followed by depth of cut and cutting speed. In fig.13, feed rate alone has the maximum spread in $S / N$ ratio curve from the mean line whereas cutting speed and depth of cut remain close to the mean of $\mathrm{S} / \mathrm{N}$ ratio indicating lowest noise signal received.

$\left.\mathrm{S} / \mathrm{N}=-10 * \log \left(\Sigma\left(\mathrm{Y}^{2}\right) / \mathrm{n}\right)\right)$

Table 2. Response analysis for Flank wear occurred on Uncoated $c B N$ insert

\begin{tabular}{|c|c|c|c|}
\hline Level & Vc $(\mathrm{m} / \mathrm{min})$ & $\mathrm{ap}(\mathrm{mm})$ & $\mathrm{f}(\mathrm{mm} / \mathrm{rev})$ \\
\hline 1 & -40.29 & -43.26 & -39.95 \\
\hline 2 & -42.88 & -40.10 & -41.38 \\
\hline 3 & -42.29 & -42.10 & -44.13 \\
\hline Delta & 2.59 & 3.15 & 4.19 \\
\hline Rank & 3 & 2 & 1 \\
\hline
\end{tabular}

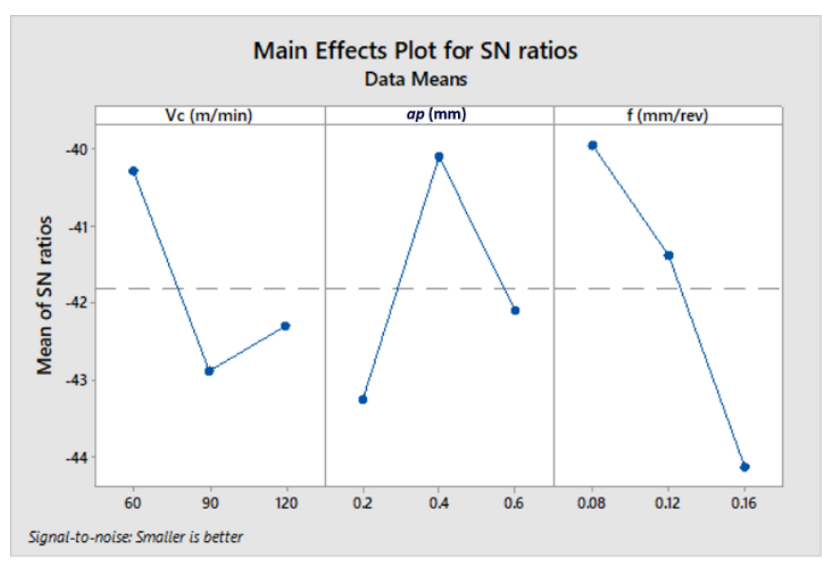

Fig. 12 S/N ratio for uncoated $c B N$ insert

Table 3. Response analysis for Flank wear occurred on Coated cBN insert

\begin{tabular}{|c|c|c|c|}
\hline Level & $\mathrm{Vc}(\mathrm{m} / \mathrm{min})$ & $\mathrm{ap}(\mathrm{mm})$ & $\mathrm{f}(\mathrm{mm} / \mathrm{rev})$ \\
\hline 1 & -41.16 & -41.29 & -39.85 \\
\hline 2 & -42.01 & -41.55 & -41.87 \\
\hline 3 & -41.41 & -41.75 & -42.87 \\
\hline Delta & 0.87 & 0.47 & 3.02 \\
\hline Rank & 2 & 3 & 1 \\
\hline
\end{tabular}

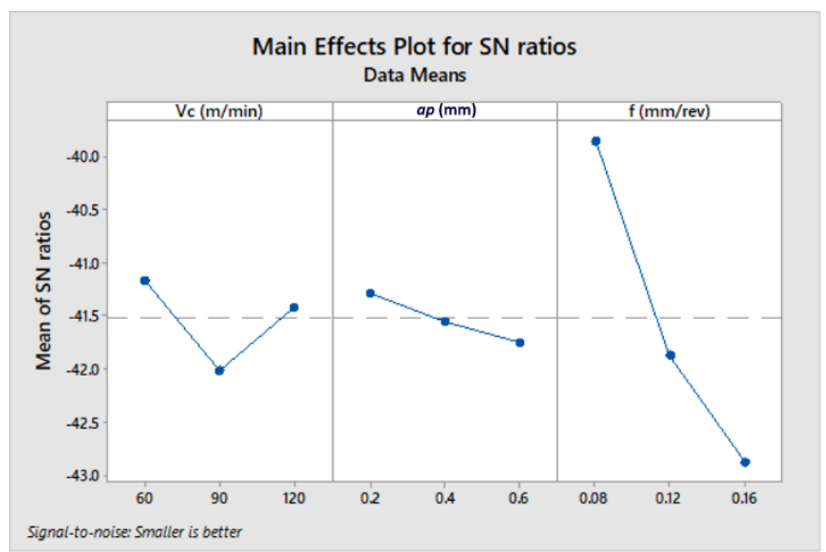

Fig. 13 S/N ratio for Coated $(A / C r N) C B N$ insert.

Fig.14 shows the bar diagram of flank wear Vs cutting speed keeping the feed rate at $0.08 \mathrm{~mm} / \mathrm{rev}, 0.12 \mathrm{~mm} / \mathrm{rev}$ and $0.16 \mathrm{~mm} / \mathrm{rev}$ in $\mathrm{a}, \mathrm{b}, \mathrm{c}$ respectively. Coated $\mathrm{cBN}$ inserts has reduced flank wear when compared with the uncoated cBN. Flank wear seems to be reduced by providing AICrN coat on $\mathrm{cBN}$ insert as they form a thermal barrier. AICrN has $15 \%$ reduced flank wear than the uncoated cBN insert which is similar to the other researcher's report [Ramana 2021]. Flank wear shown in fig. 15 and 16 represents the uncoated and coated $\mathrm{cBN}$ inserts after machining at $\mathrm{Vc}_{\mathrm{c}} 60$ $\mathrm{m} / \mathrm{min}, \mathrm{d}-0.2 \mathrm{~mm}$ and $\mathrm{f}-0.08 \mathrm{~mm} / \mathrm{rev}$. This shows that the coated $\mathrm{cBN}$ has reduced flank wear than the uncoated $\mathrm{cBN}$ insert.

The coated tools have considerable reduced affinity towards the work piece material and also acts as good lubricating element during workpiece tool interactions, hence the coated tools perform better than the uncoated tool, the coating also acts as a thermal barrier lowering the hot hardness of the tool preventing the softening of tool during machining. It is also observed that the metal adhesion caused crater wear has occured in the uncoated insert during the very early stage of machining. The increase in cutting speed results in increase in the 
temperature and thus hardness of the tool decreases. Cluster of chips rubs the newly generated surface and promotes wear propogation on the flank side of the tool.
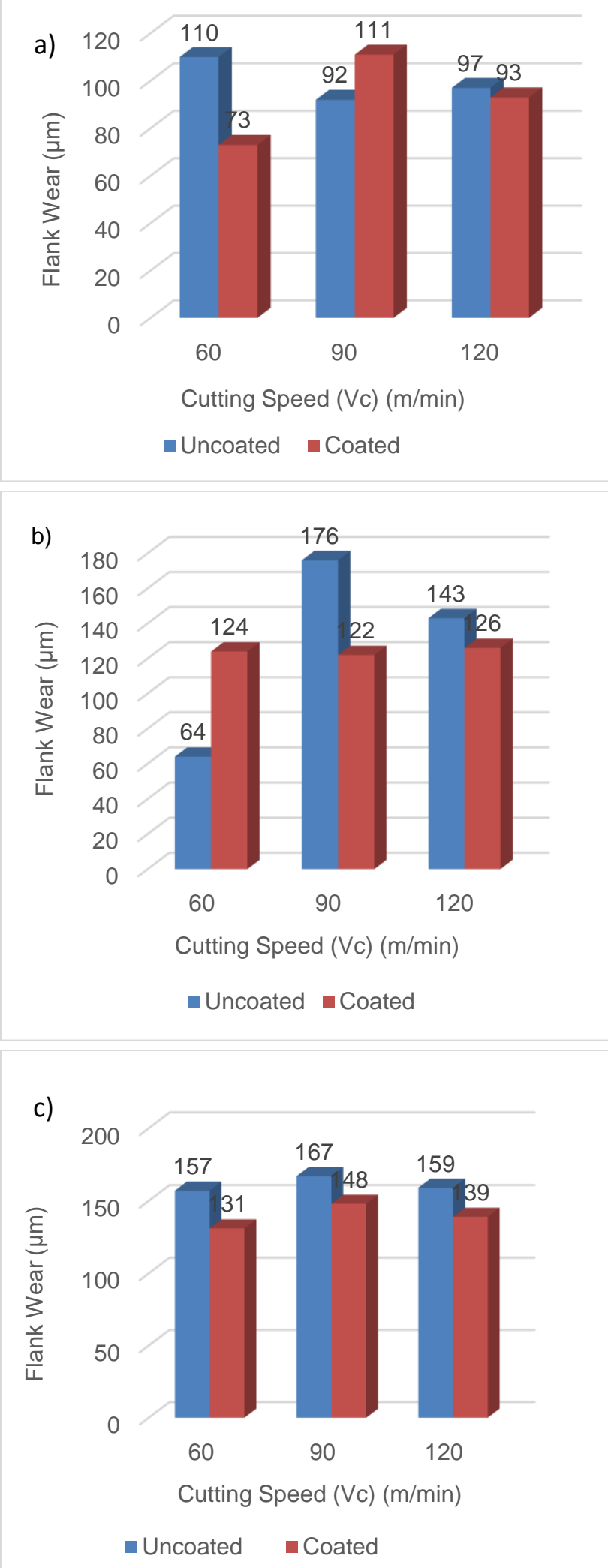

Fig. 14 Flank Wear analysis with coated and uncoated cBN tool at varying feed rates : (a) $f-0.08 \mathrm{~mm} / \mathrm{rev}$ b) $f-0.12$ $\mathrm{mm} / \mathrm{rev}$ and c) $f-0.16 \mathrm{~mm} / \mathrm{rev}$.

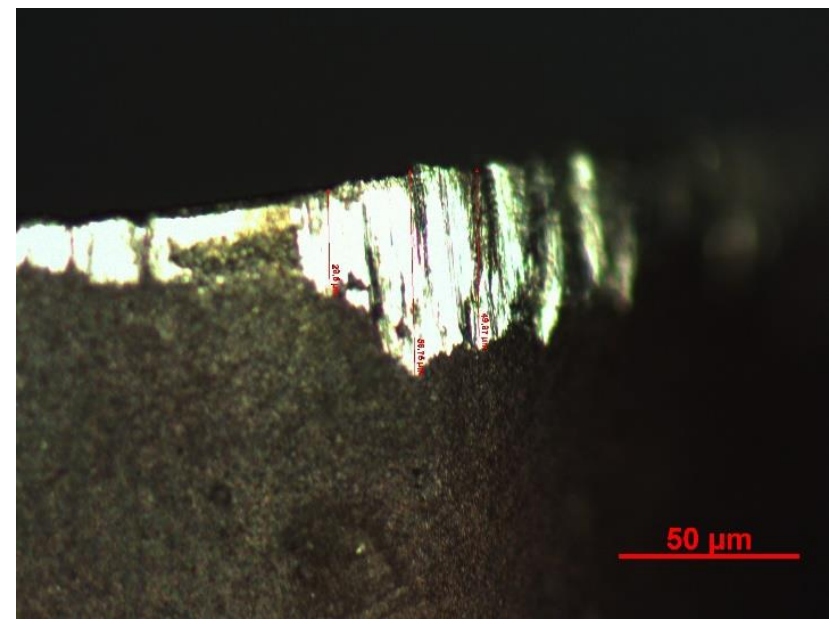

Fig. 15 Flank Wear occured on the uncoated CBN insert.

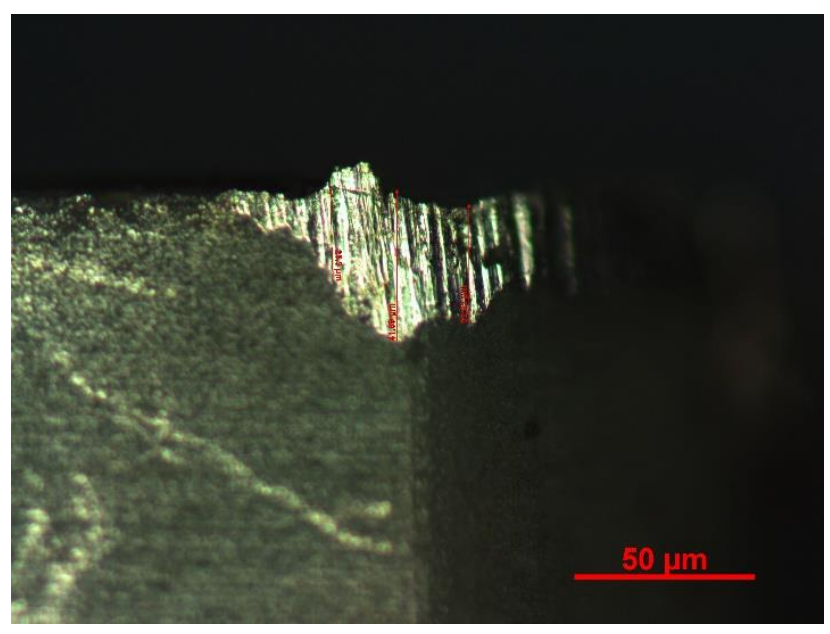

Fig. 16 Flank Wear occured on the coated CBN insert.

\subsection{Surface Roughness Analysis}

Surface roughness analysis turned to be very much important as the product's outcome lies with this factor. In this research work surface finish obtained on the specimen after machining with coated and uncoated $\mathrm{cBN}$ insert were recorded for further analysis. The experimental condition and the surface roughness values observed after machining with Uncoated and Coated inserts are presented in table 4 . Table 5 shows the response analysis for surface roughness obtained after machining with coated cBN insert, indicating rank 1 for cutting speed, rank 2 for feed rate and rank 3 for dept of cut. Similar pattern can be seen in table 6 also which shows the analysis for the data obtained after machining with uncoated inserts. From table 5 and table 6 it can be inferred that surface roughness significantly depends on the cutting speed. Figure 17 and 18 shows surface roughness of workpiece machined with coated and uncoated $\mathrm{cBN}$ insert respectively, indicating the maximum noise signal comes from cutting speed, followed by feed rate and depth of cut. Figure 19 shows the comparative analysis of the surface roughness values obtained after machining with coated and uncoated $\mathrm{cBN}$ inserts at varying cutting speeds from $60 \mathrm{~m} / \mathrm{min}$ to $120 \mathrm{~m} / \mathrm{min}$. Comparative analysis shows that coated $\mathrm{cBN}$ has lower surface roughness than the uncoated $c B N$ insert as the cutting speeds increases. At higher cutting speed the percentage of surface roughness drops by $10 \%$ while machining at 
lower cutting speed, surface roughness drop to $7-8 \%$ for the uncoated $\mathrm{cBN}$ insert. Increase in the cutting speed has reduced the surface roughness of the machining specifically while machining with AICrN coated cBN insert [Pawade 2011]. From the fig.7, it can be seen that AICrN coated tool tip experiences high temperature whereas rest of the tool remains at lower temperature which results in reduced surface roughness in the workpiece. Coating acts as an effective lubricating agent lowering the friction at the cutting interface. This phenomena helps in reducing the formation of built-up edges (BUE) during machining that results in lower surface roughness on the newly machined surface.

Table 4. Surface roughness data with machining parameters.

\begin{tabular}{|c|c|c|c|c|}
\hline $\begin{array}{c}\text { Cutting } \\
\text { speed } \\
\text { Vc } \\
(\mathrm{m} / \mathrm{min})\end{array}$ & $\begin{array}{c}\text { Depth } \\
\text { of cut } \\
\text { ap } \\
(\mathrm{mm})\end{array}$ & Feed rate & $\begin{array}{c}\text { Surface } \\
\text { Roughness }\end{array}$ & $\begin{array}{l}\text { Surface } \\
\text { Roughness } \\
\text { UC }(\mathrm{ma} \mu \mathrm{m})\end{array}$ \\
\hline 60 & 0.2 & 0.08 & 935 & 853 \\
\hline 60 & 0.4 & 0.12 & 827 & 735 \\
\hline 60 & 0.6 & 0.16 & 1028 & 928 \\
\hline 90 & 0.2 & 0.12 & 673 & 742 \\
\hline 90 & 0.4 & 0.16 & 764 & 691 \\
\hline 90 & 0.6 & 0.08 & 581 & 528 \\
\hline 120 & 0.2 & 0.16 & 631 & 578 \\
\hline 120 & 0.4 & 0.08 & 507 & 457 \\
\hline 120 & 0.6 & 0.12 & 532 & 478 \\
\hline
\end{tabular}

Table 5. Response analysis for surface roughness after machining with Coated $c B N$ insert.

\begin{tabular}{|c|c|c|c|}
\hline Level & Vc $(\mathrm{m} / \mathrm{min})$ & $\mathrm{ap}(\mathrm{mm})$ & $\mathrm{f}(\mathrm{mm} / \mathrm{rev})$ \\
\hline 1 & -58.47 & -57.12 & -55.46 \\
\hline 2 & -56.22 & -55.77 & -56.11 \\
\hline 3 & -54.01 & -55.80 & -57.13 \\
\hline Delta & 4.46 & 1.35 & 1.67 \\
\hline Rank & 1 & 3 & 2 \\
\hline
\end{tabular}

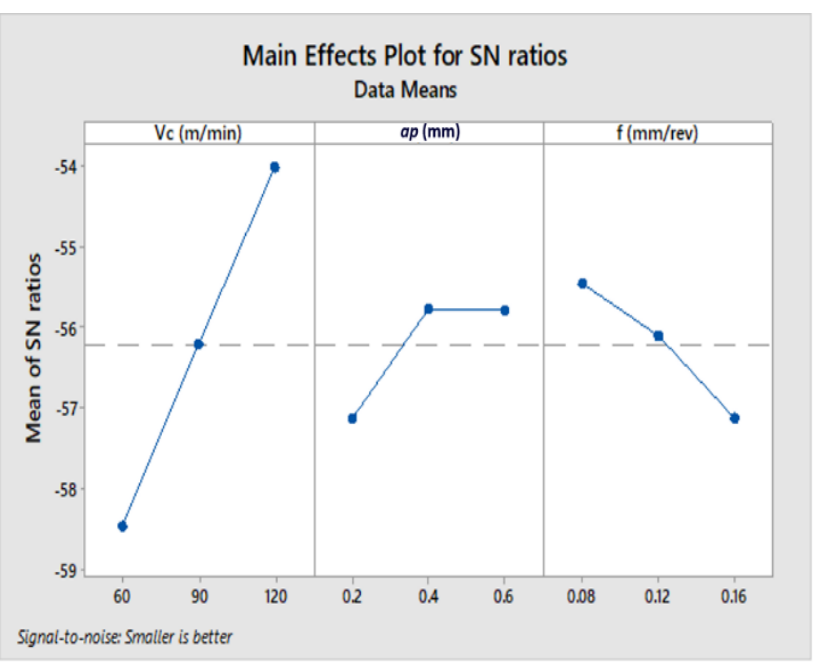

Fig.17 S/N ratio for Surface roughness obtained after machining with Coated $c B N$ insert
Table 6. Response analysis for surface roughness after machining with Uncoated $c B N$ insert.

\begin{tabular}{|c|c|c|c|}
\hline Level & Vc $(\mathrm{m} / \mathrm{min})$ & $\mathrm{d}(\mathrm{mm})$ & $\mathrm{f}(\mathrm{mm} / \mathrm{rev})$ \\
\hline 1 & -59.34 & -57.33 & -56.27 \\
\hline 2 & -56.50 & -56.70 & -56.48 \\
\hline 3 & -54.87 & -56.68 & -57.97 \\
\hline Delta & 4.46 & 0.65 & 1.70 \\
\hline Rank & 1 & 3 & 2 \\
\hline
\end{tabular}

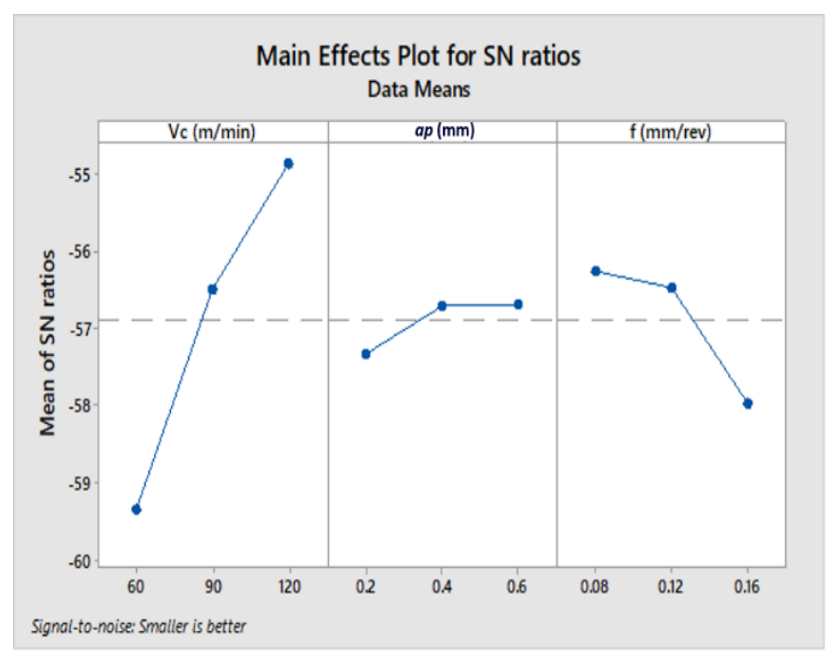

Fig.18 S/N ratio for Surface roughness obtained after machining with UnCoated $c B N$ insert

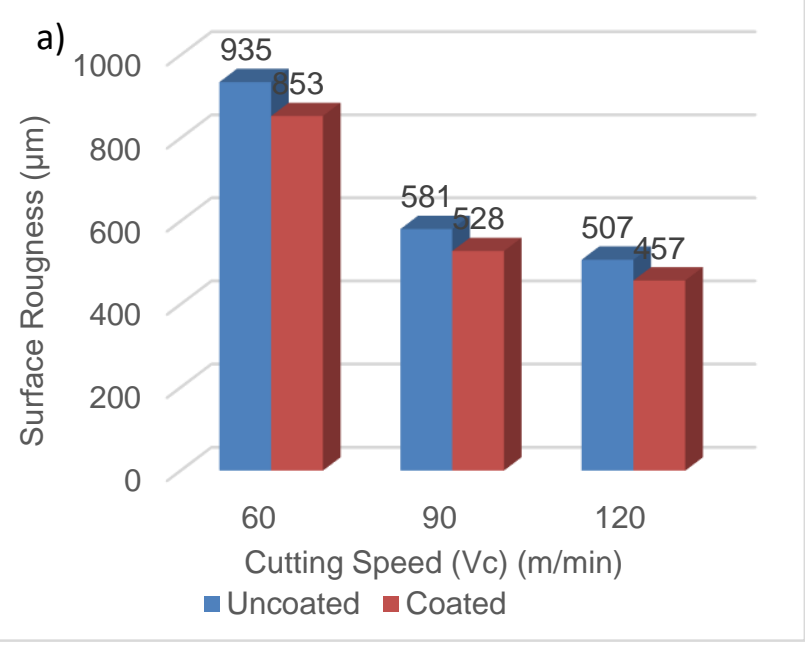

b)

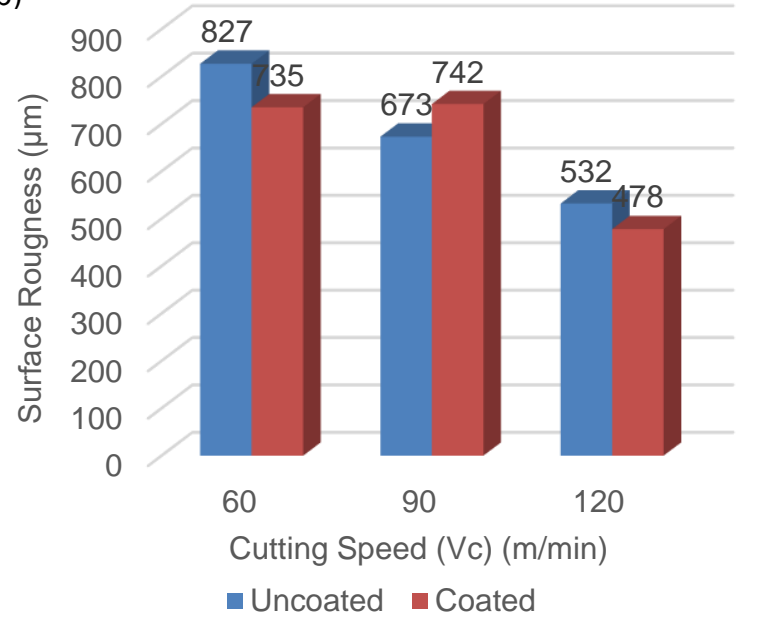




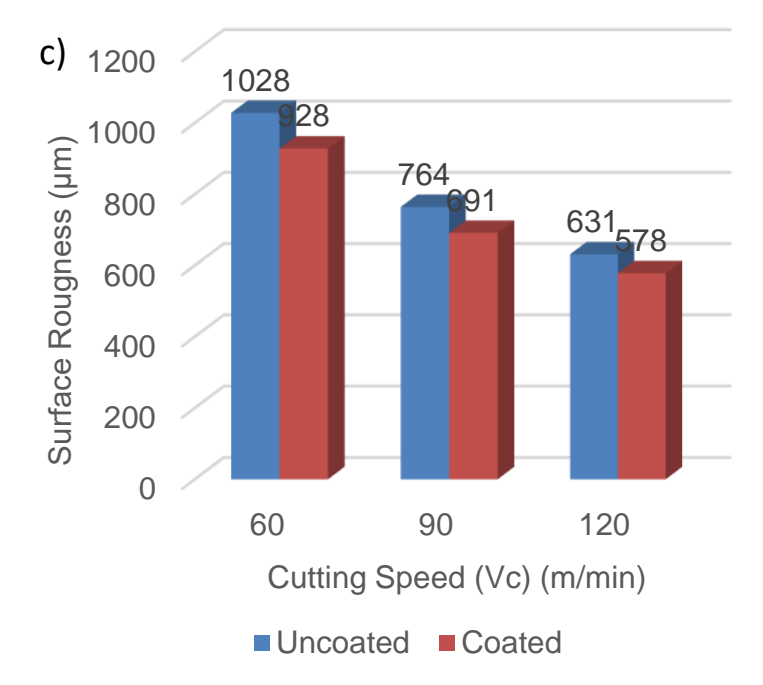

Fig. 19 Surface Roughness analysis with coated and uncoated cBN tool at different feed rates: (a) $f-0.08 \mathrm{~mm} / \mathrm{rev}$ b) $f-0.12 \mathrm{~mm} \mathrm{~mm} / \mathrm{rev}$ and c) $f-0.16 \mathrm{~mm} / \mathrm{rev}$.

\section{CONCLUSION}

AICrN coated cBN inserts shows excellent resistance to heat generated at the tool - workpiece interaction zone. AICrN shows good hot hardness value to withstand the high temperature. AlCrN coat costs only $2-3 \%$ higher than the existing cost of $\mathrm{cBN}$ insert, this slight increase in cost can provide $10-12 \%$ drop in the cutting force, $15 \%$ reduction in the flank wear and $10 \%$ reduction in the surface roughness. Taguchi analysis has optimized the process by identifying the significant parameters which influences the output parameter. Cutting force was much influenced by the feed rate and depth of cut, having lower effect due to the cutting speed. Feed rate and cutting speed has high influence on the coated cBN tool while analyzing flank wear. Surface roughness is highly influenced by the cutting speed. As the cutting speed increases from $60 \mathrm{~m} / \mathrm{min}$ to $120 \mathrm{~m} / \mathrm{min}$ for coated cBN insert the surface roughness drops from 858 $\mu \mathrm{m}$ to $578 \mu \mathrm{m}$. This study concludes that AlCrN coated cBN tool can be used for machining the difficult - to - cut materials at the cutting speed range of $120 \mathrm{~m} / \mathrm{min}$, with lower feed rate and depth of cut.

\section{REFERENCES}

[Zhang 2014] Zhang WJ, Chong YM, He B, Bello I, Lee ST. Cubic boron nitride films: properties and applications. Comprehensive hard materials. 2014. p. 607-39.

[Klocke 1999] F. Klocke, T. Krieg, Coated tools for metal cutting-features and application, Annals of CIRP 42/8 (1999) 1-19.

[Thakur 2016] A. Thakur, S. Gangopadhyay, Influence of tribological properties on the performance of uncoated, CVD and PVD coated tools in machining of Incoloy 825, Tribol Int, 102 (2016) 198-212.

[Koenig 1992] W. Koenig, R. Fritsch, D. Kammermeier, New approaches to characterizing the performance of coated cutting tools, Annals of CIRP 41/1 (1992) 49-54.
[Rech 2004] J. Rech, A. Kusiak, J.L. Battaglia, Tribological and thermal functions of cutting tool coatings, Surface Coatings \& Technology 186 (2004) 364-371.

[Toenshoff 2000] H.K. Toenshoff, C. Arendt, R. Ben Amor, Cutting of Hardened Steel, CIRP Ann. - Manuf. Technol. 49 (2000) 547-566. doi:10.1016/S0007-8506(07)63455-6.

[Dobrzanski 2005] L.A. Dobrzanski J. Mikuła Stru ture a d pr perties $f$ PVD a d CVD ated Al2O3 + TiC mixed oxide tool ceramics for dry on high speed cutting processes, J. Mater. Process. Technol. 164-165 (2005) 822-831. doi:10.1016/j.jmatprotec.2005.02.089.

[Sokovic 2006] M. Sokovic, J. Kopac, L.A. Dobrzanski, J. Mikula, K. Golombek, D. Pakula, Cutting characteristics of PVD and CVD - Coated ceramic tool inserts, Tribol. Ind. 28 (2006) 3-8.

[Vereschaka 2017] A.A. Vereschaka, S.N. Grigoriev, M.A. Volosova, A. Batako, A.S. Vereschaka, N.N. Sitnikov, A.E. Seleznev, Nano-scale multi-layered coatings for improved efficiency of ceramic cutting tools, Int. J. Adv. Manuf. Technol. 90 (2017) 27-43. doi:10.1007/s00170-016-93532.

[Kumar 2017] C.S. Kumar, S.K. Patel, Surface \& Coatings Technology Experimental and numerical investigations on the effect of varying AITiN coating thickness on hard machining performance of Al2O3-TiCN mixed ceramic $\begin{array}{llll}\text { inserts, } & \text { SCT. } & 309 & \text { (2017) }\end{array}$ doi:10.1016/j.surfcoat.2016.11.080

[Ezugwu 2005] Ezugwu E. O, Bonney J., Fadare D. A, Sales W. F, 2005, "Machining of nickelbase, Inconel 718, alloy with ceramic tools under finishing conditions with various coolant supply pressures," Journal of Materials Processing Technology, Vol. 162, pp. 609-614

[Thakur 2016] A. Thakur, S. Gangopadhyay, Influence of tribological properties on the performance of uncoated, CVD and PVD coated tools in machining of Incoloy 825, Tribol. Int. $102 \quad$ (2016) 198-212. doi:10.1016/j.triboint.2016.05.027.

[Aslantas 2012] K. Aslantas, T.I. Ucun, A. çicek, Tool life and wear mechanism of coated and uncoated Al2O3/TiCN mixed ceramic tools in turning hardened alloy steel, Wear. 274-275 (2012) 442-451. doi:10.1016/j.wear.2011.11.010.

[Kulkarni 2015] A.P. Kulkarni, V.G. Sargade, Characterization and performance of AITiN, AITiCrN, TiN/TiAIN PVD coated carbide tools while turning SS 304, Mater. Manuf. Process. 30 (2015) 748-755. doi:10.1080/10426914.2014.984217.

[Lin 2008] Y.J. Lin, A. Agrawal, Y. Fang, Wear progressions and tool life enhancement with AICrN coated inserts in high-speed dry and wet steel lathing, Wear. 264 (2008) 226-234. doi:10.1016/j.wear.2007.03.007.

[Kalss 2006] W. Kalss, A. Reiter, V. Derflinger, C. Gey, J.L. Endrino, Modern coatings in high performance cutting applications, Int. J. Refract. Met. Hard Mater. 24 (2006) 399-404. doi:10.1016/j.jjrmhm.2005.11.005.

[Reiter 2005] A.E. Reiter, V.H. Derflinger, B. Hanselmann, T. Bachmann, B. Sartory, Investigation of the properties of Al $1 \grave{A} \times \mathrm{Cr} \times \mathrm{N}$ coatings prepared by cathodic arc 
evaporation, $200 \quad$ (2005) 2114-2122. doi:10.1016/j.surfcoat.2005.01.043.

[Feng 2014] Y.P. Feng, L. Zhang, R.X. Ke, Q.L. Wan, Z. Wang, Z.H. Lu, Thermal stability and ACCEPTED MANUSCRIPTACCEPTED MANUSCRIPT oxidation behavior of AITiN, AICrN and AICrSiWN coatings, Int. J. Refract. Met. Hard Mater. 43 (2014) 241-249. doi:10.1016/j.jjrmhm.2013.11.018.

[Gutnichenko 2017] Gutnichenko, O.; Bushlya, V.; Zhou, J.; Staehl, J.-E. Tool wear and machining dynamics when turning high chromium white cast iron with pcBN tools. Wear (2017), 390-391, 253-269.

[Diaz-Álvarez 2018] Diaz-Álvarez, Jose, et al. "Pcbn performance in high speed finishing turning of inconel 718." Metals 8.8 (2018): 582.

[Zhou 2012] Zhou, Jinming, et al. "Study of surface quality in high speed turning of Inconel 718 with uncoated and coated CBN tools." The International Journal of Advanced Manufacturing Technology 58.1-4 (2012): 141-151.

[Bushlya 2013] Bushlya, Volodymyr, et al. "Performance and wear mechanisms of whisker-reinforced alumina, coated and uncoated PCBN tools when high-speed turning aged Inconel 718." The International Journal of Advanced Manufacturing Technology (2013) 66.9-12.

[Nur R 2021] Nur, R.; Yusof, N.M.; Sudin, I.; Nor, F.M.; Kurniawan, D. Determination of Energy Consumption during Turning of Hardened Stainless Steel Using Resultant Cutting Force. Metals 2021, 11, 565. https://doi.org/10.3390/ met11040565

[Ogedengbe 2012] Ogedengbe, T. S., A. P. Okediji, A. A Yussouf, O. A. Aderoba, O. A. Abiola, I. O. Alabi, and O. I. Alonge. "The effects of heat generation on cutting tool and machined workpiece." In Journal of Physics: Conference Series, vol. 1378, no. 2, p. 022012. IOP Publishing, 2019.

[Ramana 2021] Ramana, M. Venkata, G. Krishna Mohana Rao, Bidya Sagar, Ravi Kumar Panthangi, and BV Raja Ravi Kumar. "Optimization of surface roughness and tool wear in sustainable dry turning of Iron based Nickel A286 alloy using Taguchi's method." Cleaner Engineering and Technology 2 (2021): 100034.

[Pawade 2011] Pawade, Raju Shrihari, and Suhas S. Joshi. "Multi-objective optimization of surface roughness and cutting forces in high-speed turning of Inconel 718 using Taguchi grey relational analysis (TGRA)." The International Journal of Advanced Manufacturing Technology 56, no. 14 (2011): 47-62. 